Open Access

\title{
Effect of abacavir on sustained virologic response to HCV treatment in HIV/HCV co- infected patients, Cohere in Eurocoord
}

For the Hepatitis C- working group for COHERE in Eurocoord, Colette Smit*, Joop Arends, Lars Peters, Antonella d'Arminio Montforte, Francois Dabis, Robert Zangerle, George Daikos, Christina Mussini, Josep Mallolas, Stephane de Wit, Annelies Zinkernagel, Jaime Cosin, Genevieve Chene, Dorthe Raben and Jürgen Rockstroh

\begin{abstract}
Background: Contradicting results on the effect of abacavir (ABC) on hepatitis $C$ virus (HCV) treatment responses in HIV/HCV co-infected patients have been reported. We evaluated the influence of $A B C$ on the response to pegylated interferon (pegIFN) and ribavirin (RBV)-containing HCV treatment in HIV/HCV co-infected patients in a large European cohort collaboration, including data from different European countries.

Methods: HIV/HCV co-infected patients were included if they were aged $\geq 16$ years, received peglFN alfa-2a or $2 \mathrm{~b}$ and RBV combination treatment and were enrolled in the COHERE cohort collaboration. Logistic regression was used to evaluate the impact of abacavir on achieving a sustained virologic response (SVR) to HCV treatment.

Results: In total 1309 HIV/HCV co-infected patients who had received HCV therapy were included, of whom 490 (37\%) had achieved an SVR. No statistically significant difference was seen for patients using ABC-containing regimens compared to patients using an emtricitabine + tenofovir (FTC + TDF)-containing backbone, which was the most frequently used backbone. In the multivariate analyses, patients using a protease inhibitor (PI)-boosted regimen were less likely to achieve an SVR compared to patients using a non-nucleoside reverse-transcriptase inhibitor (NNRTI)-based regimen (OR: 0.61, 95 \% Cl: 0.41-0.91). The backbone combinations zidovudine\&lamivudine (AZT $+3 T C)$ and stavudine\&lamivudine $(d 4 t+3 T C)$ were associated with lower SRV rates $(0.45(0.24-0.82)$ and $0.46(0.22-0.96)$, respectively).

Conclusion: The results of this large European cohort study validate that SVR rates are generally not affected by ABC. Use of $\mathrm{d} 4 \mathrm{~T}$ or AZT as part of the HIV treatment regimen was associated with a lower likelihood of achieving an SVR.
\end{abstract}

Keywords: HCV/HIV co-infection, HCV treatment, HCV treatment response, Abacavir

\footnotetext{
* Correspondence: Colette.smit@amc.uva.nl

Stichting HIV Monitoring, Meibergdreef 9, 1105AZ Amsterdam, The

Netherlands
} 


\section{Background}

Until recently, treatment for hepatitis $\mathrm{C}(\mathrm{HCV})$ consisted of a combination of pegylated interferon (pegIFN) and ribavirin (RBV), combined more recently with boceprevir and telaprevir or with some of the new directacting antivirals (DAA)-containing regimens. In HIV/ $\mathrm{HCV}$ co-infected patients, treatment for HCV is often administrated concomitantly with combination antiretroviral therapy (cART).

Earlier studies have reported contradicting results regarding the effect of an abacavir-based cART regimen (ABC) on HCV treatment response. For example, some studies found $A B C$ has a negative effect on sustained virologic response (SVR) in the presence of HCV therapy $[1-3]$. This may be because RBV and ABC share intracellular pathways [4], which could, theoretically, affect RBV drug concentrations and therefore the effectiveness of RBV. However, other studies found no difference in SVR between patients who received an $\mathrm{ABC}$-containing regimen in combination with $\mathrm{HCV}$ treatment and those who did not use $\mathrm{ABC}$ concomitantly with $\mathrm{HCV}$ treatment [5-8]. These discrepancies might be due to the relatively small samples sizes used in the abovementioned studies. One larger study, conducted by Berenguer et al. has already been carried out and found that $\mathrm{ABC}$ was not associated with a lower response to HCV treatment [9].

This issue of contradicting results regarding the interaction between $\mathrm{ABC}$ and $\mathrm{RBV}$ remains important for two reasons. First, even in interferon-free regimens, RBV will often be used with a large number of new DAAs. Furthermore, following the introduction of the HIV integrase inhibitor dolutegravir, which is co-formulated with $\mathrm{ABC} / 3 \mathrm{TC}$ in a fixed-dose combination, use of $\mathrm{ABC}$ with $3 \mathrm{TC}$ is expected to increase. Therefore, to validate the results of the earlier large cohort study by Berenguer et al. we aimed to examine the influence of $A B C$ on the response to pegIFN and RBV-containing $\mathrm{HCV}$ treatment in $\mathrm{HIV} / \mathrm{HCV}$ co-infected patients in a large European cohort collaboration comprising data from different European countries.

\section{Methods}

\section{Study population}

Individuals included in this study were enrolled in HIV cohorts participating in the Collaboration of Observational HIV Epidemiological Research in Europe (COHERE). COHERE is a collaboration of 33 cohorts across Europe and is part of the EuroCoord network (www.cohere.org and www.EuroCoord.net). The aim of COHERE is to conduct epidemiological research into the prognosis and outcome of HIV-infected individuals, which the individual participating cohorts cannot address themselves because of small sample sizes. Participating cohorts were approved by a local ethics committee or institutional review board. The study included all HIV-positive individuals with a positive HCV RNA test result who were aged 16 years or older at the time of HIV diagnosis and who had started cART after 1 January 1998. Twelve cohorts across 9 European countries, totalling 1309 patients, provided data for the present analysis: AHIVCOS $(n=39)$, AMACS $(n=9)$, ATHENA $(n=140)$, BONN/COLOGNE $(n=3)$, EUROSIDA $(n=219), \quad$ HEPAVIH $(n=287)$, ICONA $(n=102)$, MODENA $(n=37)$, PISCIS $(n=49)$, The Swiss Cohort Study $(n=285)$, St Pierre Cohort Brussels $(n=25)$, VACH $(n=114)$. Participating cohorts adhere to the local ethics requirements, cohorts with ethics approval and individual patient written informed consent are AHIVCOS, AMACS, HEPAVIH, ICONA, MODENA, The Swiss Cohort Study, Eurosida and PISCIS. The remaining cohorts did not require ethics approval according to the national legislation (Further details of ethical requirements can be found in Additional file 1). All patients included in the present analysis received anti$\mathrm{HCV}$ treatment that included the combined use of pegIFN alfa- $2 \mathrm{a}$ or $2 \mathrm{~b}$ and RBV at standard doses, with a usual duration of 24 or 48 weeks, depending on HCV genotype. Data on the use of boceprevir and telaprevir was not available at the time of database closure. As treatment response in patients with an acute HCV infection might differ from the treatment response in chronically infected patients, patients with less than 6 months between the first available positive $\mathrm{HCV}$ test result and the start of anti-HCV treatment (i.e., acute $\mathrm{HCV}$ infection) were excluded $(n=183)$. To assess the extent of liver fibrosis, aspartate amino transferase-to-platelet ratio (APRI) scores were calculated. APRI is a non-invasive method to assess liver fibrosis that combines AST levels and platelets counts [10]; an APRI score $>1.5$ correlates with severe fibrosis. The main outcome of interest was SVR, defined as a negative HCV RNA test result 24 weeks after treatment discontinuation in patients treated for chronic HCV infection.

\section{Statistical analysis}

Logistic regression was used to identify factors associated with achieving SVR. Treatment of HIV was categorised as protease inhibitor (PI)-unboosted, PI-boosted, nonnucleoside reverse transcriptase inhibitor (NNRTI)-based, PI/NNRTI-based regimens and a fifth category including patients who had started cART after starting HCV treatment. The NRTI backbone was categorised according to the most commonly-used combinations: abacavir + lamivudine (ABC + 3TC), zidovudine + lamivudine (AZT + 3TC), emtricitabine + tenofovir $(\mathrm{FTC}+\mathrm{TDF})$, tenofovir + lamivudine (TDF $+3 \mathrm{TC})$, tenofovir + abacavir $(\mathrm{TDF}+\mathrm{ABC})$, stavudine + lamivudine $(\mathrm{d} 4 \mathrm{~T}+3 \mathrm{TC})$, other combinations, and, finally, a separate group of 242 
patients who started cART after receiving HCV treatment. To account for the shift from fixed dosing of RBV to weight-based use of RBV, we assumed that most patients received weight-based RBV doses from 2006 onwards and, therefore, analyses were adjusted for calendar year of starting HCV treatment.

Baseline characteristics of patients achieving an SVR were compared to non-responders using Student's $t$-test for the continuous variables and the Chi-square test for the categorical variables. Predictors for achieving an SVR were assessed by calculating odds ratios (OR) with a $95 \%$ confidence interval $(\mathrm{CI})$ using a logistic regression model. Multivariate models were built using forward-stepwise techniques. Variables with a $p$ value $<0.2$ in the univariate analyses were considered as potential independent determinants and included in the multivariate analysis. A $p$-value $<0.05$ was considered statistically significant. Interactions in the final model were tested. All analyses were performed using SAS version 9.3.

\section{Results \\ Study population}

We analysed data from 1309 HIV-infected patients with a chronic HCV infection who had been prescribed a combination of pegIFN and RBV between 1998 and 2011. The most common genotype was HCV genotype 1 $(n=536,40 \%)$ (Table 1$)$. The median duration of anti$\mathrm{HCV}$ treatment was 31 weeks (inter quartile range (IQR): 16-49). Of the 1309 patients, 868 completed the full course of therapy (i.e., 24-48 weeks) with pegIFN and RBV, whereas 441 prematurely discontinued treatment before week 24 because of side effects or lack of virologic response. The proportion of patients who discontinued HCV treatment before week 24 was higher among patients on PI and PI-boosted regimens (42 and $38 \%$, respectively) compared to patients on an NNRTIcontaining regimen (30\%, $p=0.09$ ). The proportion of patients who prematurely discontinued HCV treatment did not differ between the different NRTI-backbone combinations $(p=0.23)$. Haemoglobin levels were more likely to drop by more than $2.5 \mathrm{~g} / \mathrm{dl}$ compared to baseline in patients who prematurely discontinued $\mathrm{HCV}$ treatment $(46 \%)$ than in those who received HCV treatment for 24 or 48 weeks (31 and $23 \%$, respectively; $p<0.0001)$.

Baseline clinical characteristics at the start of $\mathrm{HCV}$ treatment of the included patients are shown in Table 1. Thirty-four percent of the patients used a PI-boosted cART regimen. A combination of FTC + TDF was the most frequently used NRTI backbone (20\%). In total, 233 patients used an $\mathrm{ABC}$-containing NRT combination: 189 used $\mathrm{ABC}+3 \mathrm{TC}(14 \%)$ and 44 used $\mathrm{ABC}+\mathrm{TDF}$ (3\%).

\section{SVR}

In total, 490 (37\%) patients achieved SVR. The proportion of patients with a baseline CD4 cell count $\geq 500$ cells/ $\mu \mathrm{l}$ was significantly higher among patients who achieved an SVR (41\% vs $35 \% ; p=0.02$ ). Patients with genotype 1 or 4 were significantly less likely to achieve SVR than patients with genotypes 2 or $3(p<0.0001)$.

The SVR rates ranged from $30 \%$ for patients on a regimen that included a PI and an NNRTI to $46 \%$ for those who were treated with an NNRTI-containing combination $(p=0.03)$. When stratified according to NRTIbackbone, the SVR rate was $24 \%$ amongst patients using a d4T\&3TC backbone, and the SVR rate was $48 \%$ in patients using a TDF\&3TC backbone. The SVR rate was $38 \%$ for patients with a ABC\&AZT backbone and $39 \%$ for those with a TDF\&ABC backbone.

\section{Predictors of SVR}

Table 2 shows the predictive factors for SVR in HCV/ $\mathrm{HIV}$ co-infected patients receiving anti-HCV treatment. In the univariate analyses, $\mathrm{ABC}$-containing backbones were not associated with a higher or lower likelihood of achieving an SVR. Longer duration of HCV treatment compared to less than 24 weeks of treatment, men who have sex with men, HCV genotypes 2 and 3, lower APRI score, and a larger decline in haemoglobin levels were associated with a higher likelihood of achieving an SVR. Starting HCV treatment before 2003 was significantly associated with a lower likelihood of achieving an SVR compared to starting in or after 2006. Patients who started between 2003 and 2005 were non-significantly less likely to achieve an SVR. Patients using a PI-boosted cART regimen or an AZT + 3TC NRTI backbone were also less likely to achieve an SVR.

In the multivariate analyses, after adjustment for differences in clinical and demographic variables, there remained no association between $\mathrm{ABC}$-containing regimens and a higher or lower likelihood of achieving an SVR. A boosted PI regimen remained significantly associated with a lower probability of achieving an SVR compared to NNRTI-based regimens. Overall, the different backbones, and most importantly the use of $A B C$, were not associated with a low SVR after adjustment for differences in clinical and demographical variables, with the exception of the AZT $+3 \mathrm{TC}$ and $\mathrm{d} 4 \mathrm{t}+3 \mathrm{TC}$ combinations. Patients using these backbones were less likely to achieve an SVR $(0.45(0.24-0.82)$ and $0.46(0.22-$ $0.96)$, respectively). No statistically significant difference was seen between patients using $\mathrm{ABC}$-containing regimens and those using an FTC + TDF-containing backbone. No statistically significant difference was observed between patients who started cART after receiving $\mathrm{HCV}$ treatment and those using an FTC + TDF-containing backbone. Finally, earlier calendar year of starting HCV 
Table 1 Demographic and clinical characteristics at start of anti-hepatitis C virus (HCV) treatment of chronically HIV/HCV co-infected patients, 1998-2011

\begin{tabular}{|c|c|c|c|c|}
\hline & \multicolumn{4}{|c|}{ Sustained virologic response } \\
\hline & Total & No & Yes & $p$-value \\
\hline Number of patients (\%) & 1309 & $819(63)^{a}$ & $490(37)^{a}$ & \\
\hline Age baseline, years & $42(38-46)$ & $42(38-46)$ & $42(37-46)$ & 0.04 \\
\hline Baseline BMI & & & & $<0.0001$ \\
\hline$<25$ & $329\left(25^{b}\right)$ & $234(71)$ & $95(29)$ & \\
\hline$>=25$ & $123(9)$ & $96(78)$ & $27(22)$ & \\
\hline Unknown & $857(66)$ & $489(57)$ & $368(43)$ & \\
\hline Gender & & & & 0.57 \\
\hline Male & $960(73)$ & $605(63)$ & $355(37)$ & \\
\hline Female & $349(39)$ & $214(61)$ & $135(39)$ & \\
\hline HIV transmission route: & & & & 0.05 \\
\hline Men who have sex with men & $175(13)$ & $91(52)$ & $84(48)$ & \\
\hline Male, injection drug use (IDU) & $595(45)$ & $393(66)$ & $202(34)$ & \\
\hline Female IDU & $209(16)$ & $127(61)$ & $82(39)$ & \\
\hline Male heterosexual & $84(6)$ & $55(65)$ & $29(35)$ & \\
\hline Female heterosexual & $96(7)$ & $62(65)$ & $34(35)$ & \\
\hline Male other/unknown & $106(8)$ & $66(62)$ & $40(38)$ & \\
\hline Female other/unknown & $44(3)$ & $25(57)$ & $19(43)$ & \\
\hline Region of origin: & & & & 0.06 \\
\hline Western & $1101(84)$ & $700(64)$ & $401(36)$ & \\
\hline Other & $116(9)$ & $72(62)$ & $44(38)$ & \\
\hline Unknown & $92(7)$ & $47(51)$ & $45(49)$ & \\
\hline \multicolumn{5}{|l|}{ CD4 at baseline (cells/ $\mu \mathrm{l})$} \\
\hline $0-349$ & $264(20)$ & $163(62)$ & $101(38)$ & 0.02 \\
\hline $350-499$ & $306(23)$ & $194(63)$ & $112(37)$ & \\
\hline$>=500$ & $491(38)$ & $288(59)$ & $203(41)$ & \\
\hline Missing & $248(19)$ & $174(70)$ & $74(30)$ & \\
\hline Nadir CD4 (cells/ $\mu$ l) & & & & $<0.001$ \\
\hline$<200$ & $689(53)$ & $434(63)$ & $255(37)$ & \\
\hline$>=200$ & $583(45)$ & $381(65)$ & $202(35)$ & \\
\hline Missing & $37(3)$ & $4(11)$ & $33(89)$ & \\
\hline HIV RNA levels at baseline (copies/ml) & & & & 0.99 \\
\hline$<=400$ & $1082(83)$ & $677(63)$ & $405(37)$ & \\
\hline$>400$ & $227(17)$ & $142(63)$ & $85(37)$ & \\
\hline Hepatitis B virus co-infection & & & & 0.64 \\
\hline No & $1214(93)$ & $762(63)$ & $452(37)$ & \\
\hline Yes & $53(4)$ & $30(57)$ & $23(43)$ & \\
\hline Unknown & $42(3)$ & $27(64)$ & $14(33)$ & \\
\hline HCV RNA load at baseline & & & & $<0.0001$ \\
\hline$<600,000$ & $222(17)$ & $99(45)$ & $123(55)$ & \\
\hline$\geq 600,000$ & $724(55)$ & $485(67)$ & $239(33)$ & \\
\hline Missing & $363(28)$ & $235(65)$ & $128(35)$ & \\
\hline
\end{tabular}


Table 1 Demographic and clinical characteristics at start of anti-hepatitis C virus (HCV) treatment of chronically HIV/HCV co-infected patients, 1998-2011 (Continued)

\begin{tabular}{|c|c|c|c|c|}
\hline HCV genotypes & & & & $<0.0001$ \\
\hline 1 & $82(6)$ & $53(65)$ & $29(35)$ & \\
\hline $1 a$ & $307(23)$ & $234(76)$ & $83(27)$ & \\
\hline $1 b$ & $147(11)$ & $108(73)$ & $39(27)$ & \\
\hline $2 \& 3$ & $315(24)$ & $154(49)$ & $161(51)$ & \\
\hline 4 & $143(11)$ & $103(72)$ & $40(28)$ & \\
\hline Other/unknown & $315(24)$ & $177(56)$ & $138(44)$ & \\
\hline APRI' score: & & & & $<0.0001$ \\
\hline$<0.5$ & $409(31)$ & $206(50)$ & $203(50)$ & \\
\hline $0.5-1.5$ & $426(32)$ & $312(73)$ & $114(27)$ & \\
\hline$>=1.5$ & $195(15)$ & $155(79)$ & $40(21)$ & \\
\hline Unknown & $279(21)$ & $146(52)$ & $133(48)$ & \\
\hline Decline in haemoglobin $(\mathrm{g} / \mathrm{dl})$ & & & & 0.0017 \\
\hline No decline & $179(14)$ & $126(70)$ & $53(30)$ & \\
\hline$<=2.5$ & $227(17)$ & $157(69)$ & $70(31)$ & \\
\hline$>2.5$ & $230(18)$ & $127(55)$ & $103(45)$ & \\
\hline Missing & $637(49)$ & $409(64)$ & $264(41)$ & \\
\hline Duration of HCV treatment in weeks & & & & $<0.0001$ \\
\hline$<=24$ & $496(38)$ & $390(79)$ & $106(21)$ & \\
\hline $24-48$ & $437(33)$ & $242(55)$ & $195(45)$ & \\
\hline$>48$ & $376(29)$ & $187(50)$ & $189(50)$ & \\
\hline Calendar year of start HCV treatment & & & & $<0.0001$ \\
\hline$<=2003$ & $266(20)$ & $201(76)$ & $65(24)$ & \\
\hline $2003-2006$ & $421(32)$ & $258(61)$ & $163(39)$ & \\
\hline$>=2006$ & $622(48)$ & $360(58)$ & $262(42)$ & \\
\hline CART regimen & & & & 0.003 \\
\hline $\mathrm{Pl}$ & $158(12)$ & $104(66)$ & $54(34)$ & \\
\hline Boosted PI & $444(34)$ & $296(67)$ & $148(33)$ & \\
\hline NNRTI & $284(22)$ & $154(54)$ & $130(46)$ & \\
\hline $\mathrm{PI}+\mathrm{NNRTI}$ & $50(6)$ & $35(70)$ & $15(30)$ & \\
\hline No PI and/or NNRTI & $131(10)$ & $90(69)$ & $41(31)$ & \\
\hline no CART & $242(18)$ & $140(58)$ & $102(42)$ & \\
\hline Backbone & & & & $<0.0001$ \\
\hline Start after HCV treatment & $242(18)$ & $140(58)$ & $102(42)$ & \\
\hline$A B C+3 T C$ & $189(14)$ & $117(62)$ & $72(38)$ & \\
\hline$A Z T+3 T C$ & $140(11)$ & $99(62)$ & $41(29)$ & \\
\hline $\mathrm{FTC}+\mathrm{TDF}$ & $262(20)$ & $147(56)$ & $115(44)$ & \\
\hline $\mathrm{TDF}+3 \mathrm{TC}$ & $130(10)$ & $68(52)$ & $62(48)$ & \\
\hline $\mathrm{TDF}+\mathrm{ABC}$ & $44(3)$ & $27(61)$ & $17(39)$ & \\
\hline $\mathrm{d} 4 \mathrm{~T}+3 \mathrm{TC}$ & $90(7)$ & $68(76)$ & $22(24)$ & \\
\hline other & $212(16)$ & $153(72)$ & $59(28)$ & \\
\hline
\end{tabular}

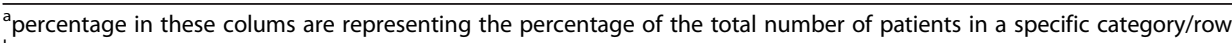

${ }^{\mathrm{b}}$ Percentage from total number of patients included in this study $(n=1309)$

${ }^{C} \mathrm{APRI}$, aspartate amino transferase-to-platelet ratio; PI, protease inhibitor; NNRTI, non-nucleoside reverse transcriptase; NRTI, nucleoside analog reverse-transcriptaseinhibitor; ABC, abacavir, 3TC, lamivudine; AZT, zidovudine; FTC, emtricitabine; TDF, tenofovir; d4T, stavudine 
Table 2 Association of predictive factors with sustained virologic response among patients receiving anti-hepatitis C virus (HCV) treatment in chronically HCV/HIV co-infected patients, COHERE collaboration, 1998-2011, using logistic regression with forward selection of the variables included in the multivariate model

\begin{tabular}{|c|c|c|c|c|c|}
\hline & & Univariate & $p$-value & Multivariate & $p$-value \\
\hline & & $\begin{array}{l}\text { Odds ratio (95 \% } \\
\text { confidence interval) }\end{array}$ & & $\begin{array}{l}\text { Odds ratio ( } 95 \% \\
\text { confidence interval) }\end{array}$ & \\
\hline Age at start HCV treatment (years) & $16-34$ & 1 & & 1 & \\
\hline & $35-49$ & $0.71(0.51-0.99)$ & 0.04 & $0.80(0.52-1.23)$ & 0.29 \\
\hline & $>=50$ & $0.68(0.43-1.07)$ & 0.10 & $0.58(0.32-1.04)$ & 0.06 \\
\hline Duration HCV treatment in weeks & $<24$ & 1 & & 1 & \\
\hline & $24-48$ & $2.97(2.23-3.95)$ & $<0.0001$ & $2.85(2.0-4.05)$ & $<0.0001$ \\
\hline & $>48$ & $3.72(2.77-4.99)$ & $<0.0001$ & $4.92(3.43-7.08)$ & $<0.0001$ \\
\hline Calendar year of starting HCV treatment & $<=2003$ & $0.45(0.32-0.64)$ & $<0.0001$ & $0.41(0.29-0.71)$ & 0.0008 \\
\hline & 2003-2005 & $0.90(0.69-1.18)$ & 0.27 & $1.10(0.78-1.59)$ & 0.62 \\
\hline & $>=2006$ & 1 & & 1 & \\
\hline BMl & $<25$ & 1 & & 1 & \\
\hline & $>=25$ & $0.69(0.42-1.13)$ & 0.14 & $1.01(0.58-1.76)$ & 0.97 \\
\hline & unknown & $1.85(1.41-2.44)$ & $<0.0001$ & $6.12(3.99-9.38)$ & $<0.0001$ \\
\hline Gender & Male & 1 & 0.57 & & - \\
\hline & Female & $1.08(0.84-1.38)$ & & & \\
\hline HIV transmission route: & MSM & $1.80(1.28-2.53)$ & 0.0008 & & - \\
\hline & Male injection drug us (IDU) & 1 & & & \\
\hline & Female IDU & $1.26(0.91-1.74)$ & 0.17 & & \\
\hline & Male heterosexual & $1.03(0.63-1.66)$ & 0.92 & & \\
\hline & Female heterosexual & $1.07(0.68-1.68)$ & 0.77 & & \\
\hline & Male other/unknown & $1.18(0.77-1.81)$ & 0.45 & & \\
\hline & Female other/unknown & $1.48(0.80-2.75)$ & 0.21 & & \\
\hline Region of origin: & Western & 1 & & & - \\
\hline & Other & $1.07(0.72-1.58)$ & 0.75 & & \\
\hline & Unknown & $1.67(1.09-2.56)$ & 0.02 & & \\
\hline HIV RNA levels at baseline (copies/ml) & $<=400$ & $1.00(0.74-1.34)$ & 0.99 & & - \\
\hline & $>400$ & 1 & & & \\
\hline Hepatitis B virus co-infection & No & 1 & & & - \\
\hline & Yes & $1.29(0.74-2.25)$ & 0.37 & & \\
\hline & unknown & $0.94(0.49-1.78)$ & 0.58 & & \\
\hline Nadir CD4 (cells/ $\mu \mathrm{l})$ & $<200$ & 1 & & 1 & \\
\hline & $>=200$ & $0.90(0.72-1.14)$ & 0.38 & $0.80(0.57-1.12)$ & 0.19 \\
\hline CD4 at baseline (cells/ $\mu \mathrm{l})$ & $0-349$ & 1 & & 1 & \\
\hline & $350-499$ & $0.93(0.66-1.31)$ & 0.68 & $0.69(0.45-1.07)$ & 0.09 \\
\hline & $>=500$ & $1.14(0.84-1.54)$ & 0.40 & $0.94(0.62-1.42)$ & 0.75 \\
\hline & missing & $0.69(0.48-0.99)$ & 0.04 & $0.10(0.05-0.19)$ & $<0.0001$ \\
\hline HCV RNA load at baseline & $<600,000$ & $2.52(1.86-3.43)$ & $<0.0001$ & $2.06(1.38-3.06)$ & 0.0004 \\
\hline & $\geq 600,000$ & 1 & & 1 & \\
\hline & missing & $1.11(0.85-1.44)$ & 0.46 & $1.41(0.90-2.20)$ & 0.13 \\
\hline HCV genotypes & 1 & $0.52(0.32-0.87)$ & 0.02 & $0.27(0.14-0.51)$ & $<0.0001$ \\
\hline & $1 a$ & $0.35(0.25-0.50)$ & $<0.0001$ & $0.25(0.17-0.39)$ & $<0.0001$ \\
\hline & $1 b$ & $0.35(0.23-0.53)$ & $<0.0001$ & $0.28(0.16-0.47)$ & $<0.0001$ \\
\hline
\end{tabular}


Table 2 Association of predictive factors with sustained virologic response among patients receiving anti-hepatitis C virus (HCV) treatment in chronically HCV/HIV co-infected patients, COHERE collaboration, 1998-2011, using logistic regression with forward selection of the variables included in the multivariate model (Continued)

\begin{tabular}{|c|c|c|c|c|c|}
\hline & $2 \& 3$ & 1 & & 1 & \\
\hline & 4 & $0.37(0.24-0.60)$ & $<0.0001$ & $0.32(0.19-0.54)$ & $<0.0001$ \\
\hline & Other/unknown & $0.74(0.55-1.02)$ & 0.69 & $0.70(0.46-1.05)$ & 0.023 \\
\hline \multirow[t]{4}{*}{ APRI $\left.\right|^{a}$ score } & $<0.5$ & 1 & & 1 & \\
\hline & $0.5-1.5$ & $0.37(0.28-0.50)$ & $<0.0001$ & $0.41(0.29-0.58)$ & $<0.0001$ \\
\hline & $>=1.5$ & $0.26(0.18-0.39)$ & $<0.0001$ & $0.24(0.15-0.39)$ & $<0.0001$ \\
\hline & unknown & $0.92(0.68-1.25)$ & 0.61 & $0.61(0.40-0.94)$ & 0.023 \\
\hline \multirow[t]{4}{*}{ Decline in haemoglobin $(\mathrm{g} / \mathrm{dl})$} & No decline & 1 & & 1 & \\
\hline & $<=2.5$ & $1.06(0.69-1.62)$ & 0.78 & $0.89(0.52-1.51)$ & 0.66 \\
\hline & $>2.5$ & $1.93(1.28-2.92)$ & 0.002 & $1.36(0.81-2.28)$ & 0.24 \\
\hline & missing & $1.53(1.08-2.19)$ & 0.02 & $4.66(2.81-7.72)$ & $<0.0001$ \\
\hline \multirow[t]{6}{*}{ CART use: } & $\mathrm{PI}$ & $0.62(0.41-0.92)$ & 0.02 & $1.04(0.62-1.75)$ & 0.87 \\
\hline & Boosted PI & $0.59(0.44-0.80)$ & 0.0008 & $0.61(0.41-0.91)$ & 0.02 \\
\hline & NNRT & 1 & & 1 & \\
\hline & $\mathrm{PI}+\mathrm{NNRT}$ & $0.51(0.27-0.97)$ & 0.04 & $0.65(0.29-1.44)$ & 0.29 \\
\hline & No PI and/or NNRT & $0.54(0.39-0.84)$ & 0.006 & $0.78(0.44-1.39)$ & 0.39 \\
\hline & Start after HCV treatment & $0.86(0.61-1.22)$ & 0.40 & $N A^{b}$ & \\
\hline \multirow[t]{8}{*}{ NRTI backbone ${ }^{a}$} & Start after HCV treatment & $0.93(0.65-1.33)$ & 0.69 & $0.96(0.57-1.61)$ & 0.34 \\
\hline & $A B C+3 T C$ & $0.79(0.54-1.15)$ & 0.22 & $0.74(0.45-1.24)$ & 0.25 \\
\hline & $A Z T+3 T C$ & $0.53(0.34-0.82)$ & 0.004 & $0.44(0.24-0.80)$ & 0.007 \\
\hline & $\mathrm{FTC}+\mathrm{TDF}$ & 1 & & 1 & \\
\hline & $\mathrm{TDF}+3 \mathrm{TC}$ & $1.17(0.76-1.78)$ & 0.47 & $0.76(0.44-1.32)$ & 0.33 \\
\hline & $\mathrm{TDF}+\mathrm{ABC}$ & $0.81(0.42-1.55)$ & 0.51 & $0.79(0.35-1.78)$ & 0.57 \\
\hline & $d 4 T+3 T C$ & $0.41(0.24-0.71)$ & 0.001 & $0.46(0.22-0.96)$ & 0.04 \\
\hline & other & $0.50(0.34-0.73)$ & 0.0003 & $0.54(0.32-0.91)$ & 0.02 \\
\hline
\end{tabular}

${ }^{a} \mathrm{APRI}$, aspartate amino transferase-to-platelet ratio; PI, protease inhibitor; NNRTI, non-nucleoside reverse transcriptase; NRTI, nucleoside analog reverse-transcriptaseinhibitor; ABC, abacavir, 3TC, lamivudine; AZT, zidovudine; FTC, emtricitabine; TDF, tenofovir; d4T, stavudine

bodds ratio could not be calculated due to collinearity with the NRTI backbone category 'start after HCV treatment'

treatment remained significantly associated with a lower odds of achieving an SVR.

\section{Discussion}

The results of this study, conducted in an unselected cohort of HCV/HIV co-infected patients from different countries in Europe, showed no difference in response to $\mathrm{HCV}$ treatment in patients using an $\mathrm{ABC}$-containing regimen compared to those using an FTC + TDF-containing backbone. Overall, $37 \%$ of patients achieved an SVR, compared to $29 \%$ of patients on a boosted PI regimen. The response to HCV treatment did not differ between patients who used cART and those who did not.

Earlier studies have shown contradicting results for the effect of $\mathrm{ABC}[2,3,6-8]$. The results of our study, conducted in a large multi-cohort study, validate those of an earlier large cohort study into the effect of cART on HCV treatment outcome [9]. In our study, the concomitant use of $\mathrm{ABC}+3 \mathrm{TC}$ or $\mathrm{ABC}+\mathrm{TDF}$ and $\mathrm{HCV}$ treatment did not result in different SVR rates compared to the concomitant of TDF + FTC and HCV treatment, which was most frequently used in this patient population. In terms of the NRTIs used during HCV treatment, in this study AZT in combination with 3TC and $\mathrm{d} 4 \mathrm{~T}$ in combination with 3TC negatively affected the response to HCV treatment. This negative effect of these NRTIs might be due not only to the interference of $\mathrm{d} 4 \mathrm{~T}$ with RBV [11], but also the effect of AZT on lowering haemoglobin levels [12]. Moreover, according to the guidelines from the European AIDS Clinical Society, d4T and AZT use should be avoided during pegIFN and RBV treatment [13], as both PEG-IFN and RBV are also commonly known to decrease haemoglobin levels $[14,15]$. In fact, anaemia is frequently observed in patients during $\mathrm{HCV}$ therapy [12] and is often a cause for RBV dose reductions or early discontinuation of $\mathrm{HCV}$ treatment, which negatively 
impacts SVR rates [16]. On the other hand, lower haemoglobin levels have been shown to be associated with higher SVR rates [17]. This could reflect adequate weight-based RBV dosing accompanied by more side effects such as declining haemoglobin levels. Although we had no data on RBV dosing, haemoglobin measurements were available for half the patients. Consequently, we were able to calculate changes in haemoglobin levels and to use the decline in haemoglobin levels as a proxy for changes in RBV doses, assuming that a stronger decline in haemoglobin levels might be a marker for higher RBV doses. As a result of including this haemoglobin change in our analyses we observed higher SVR rates in patients with a haemoglobin decline of $2.5 \mathrm{~g} / \mathrm{dl}$ or more from baseline, which could reflect higher RBV levels. In addition, the results of a sensitivity analysis including patients with a haemoglobin decline of $>2.5 \mathrm{~g} / \mathrm{dl}$ showed that patients using the combination of AZT and 3TC remained less likely to achieve an SVR compared to patients who used FTC + TDF. Although this result was not statistically significant, the effect of AZT on lowering haemoglobin levels could have attributed to higher toxicity and early discontinuation.

Several reports have shown that weight-based dosing of $\mathrm{RBV}$ is more effective than flat dosing of RBV, and that adequate dosing of RBV is crucial to maximising HCV treatment response $[18,19]$. Consequently, there has been a shift from flat dosing to weight-based dosing over time, with most patients receiving weight-based RBV from 2006 onwards. To account for this shift and address the lack of information on RBV dosing in our study, we included calendar time of starting HCV treatment.

The composition of cART regimens has changed over time. In recent years, there has been a drop in the use of $\mathrm{AZT}$ and $\mathrm{d} 4 \mathrm{~T}$ in cART regimens; in fact the European AIDS clinical society guidelines no longer recommend inclusion of AZT and d4T in initial regimens [13]. Moreover, with the introduction of the HIV integrase inhibitor dolutegravir, use of $\mathrm{ABC}$ in combination with $3 \mathrm{TC}$ is expected to increase in the future. Therefore, to evaluate the impact of these changes over calendar time we included an interaction term between calendar time and NRTI backbones in the logistic regression model. This analysis found no statistically significant interaction and therefore we assumed that the effect of cART regimens on $\mathrm{HCV}$ treatment response does not vary with calendar time.

Our study found a significantly lower SVR in patients on a boosted PI regimens compared to those on an NNRTI-based regimen. This confirms previous reports of an association between a PI-based regimen and lower SVR rates [20]. Furthermore, Berenguer et al. also found that patients on a boosted PI were less likely to achieve an SVR, although this result was statistically nonsignificant [9]. The significant difference between a boosted PI-based regimen and an NNRTI-based regimen in our study might be due to differences in patient characteristics in the two groups: patients on a boosted PIbased regimen had significant lower CD4 counts at the time of cART initiation than patients on an NNRTI cART regimen. Since boosted PI regimens are likely to be prescribed to patients who experienced virological failure on earlier cART regimens, these patients may have been infected with HIV for a longer period of time and may have had more advanced HIV disease progression. It is also likely that these patients had been chronically infected with $\mathrm{HCV}$ for a longer period of time. As a result, these patients may have had a higher degree of liver damage, as progression to liver disease is common with $\mathrm{HCV}$ and known to be accelerated in the presence of HIV [21, 22], and therefore might have been less likely to achieve an SVR [23]. To account for the progression to liver disease and for advanced HIV disease, in the final multivariate model we included not only the APRI score, which has been shown to be a reliable marker for predicting hepatic fibrosis in $\mathrm{HIV} / \mathrm{HCV}$ coinfected patients [10], but also nadir CD4 cell count. After adjustment for differences in advanced HIV and liver disease, our study still shows a trend towards a lower probability of achieving an SVR in patients on a boosted PI regimen. Furthermore, although not statistically significant, the discontinuation rate of HCV treatment was somewhat higher in patients receiving a PI or PI-boosted cART regimen, compared to patients receiving an NNRTI cART regimen.

The primary aim of our study was to examine the influence of $\mathrm{ABC}$ on the response to pegIFN and RBVcontaining $\mathrm{HCV}$ treatment in patients already receiving cART prior to HCV treatment. However, we also included a group of patients who started cART after receiving $\mathrm{HCV}$ treatment. When we compared this group to those who were already using an FTC + TDF-containing backbone prior to starting HCV treatment, we found no statistically significant difference in SVR response rates. An explanation for this finding could be that the group of patients who started cART after HCV treatment were relatively healthy and not yet in need for HIV treatment. This assumption is supported by the large number of these patients with a high CD4 cell count at the time of $\mathrm{HCV}$ treatment initiation: median CD4 cell count in this group was 494 cells $/ \mathrm{mm}^{3}$ (interquartile range: $387-651$ ).

Finally, the number of new DAAs is increasing and, consequently, the number of treatment options that rule out the need for pegIFN will also increase substantially. In view of this development, the interaction between pegIFN and $\mathrm{ABC}$ has become less relevant. Furthermore, as the result of the growing number of treatment options, including DAA combinations without RBV, it is also likely that fewer patients will be treated with a RBV- 
containing DAA combination in the future, which might limit the clinical importance of the present findings. Nonetheless, we believe knowledge regarding a possible interaction between RBV and $\mathrm{ABC}$ remains important as some of the new DAAs may still be used in combination with RBV. Moreover, the high costs of these new DAAs could limit access to these treatment options in some regions, which might result in RBV still being used in combination with $\mathrm{ABC}$ in certain settings.

\section{Conclusions}

The results of this large European cohort study validate those of another large cohort study by showing that SVR rates are generally not affected by ABC. Use of $\mathrm{d} 4 \mathrm{~T}$ or AZT as part of the HIV treatment regimen was associated with a lower likelihood of achieving an SVR, which, in the case of AZT, might be related to its propensity to induce anaemia. A potential negative impact of a boosted PI regimen may warrant further evaluation. Finally, we found no evidence of a harmful effect of $\mathrm{ABC}$-containing regimens in future DAA and RBV combinations.

\section{Additional file}

Additional file 1: Ethics requirements for cohorts and studies for Cohere in EuroCoord. (DOC $29 \mathrm{~kb}$ )

\begin{abstract}
Abbreviations
HCV: Hepatitis C virus; CART: combination antiretroviral therapy; Cohere: Collaboration of Observational HIV Epidemiological Research in Europe; SVR: Sustained virological response; pegIFN: pegylated interferon; RBV: Ribavirin; APRI: Aspartate amino transferase-to-platelet ratio; PI: Protease inhibitor; NNRTI: Non-nucleoside reverse transcriptase; NRTI: Nucleoside analog reverse-transcriptaseinhibitor; ABC: Abacavir; 3TC: Lamivudine; AZT: Zidovudine; FTC: Emtricitabine; TDF: Tenofovir; d4T: Stavudine; OR: Odds ratio; Cl: Confidence interval; DAA: Direct-acting antivirals.

\section{Competing interests}

JA and JR declare that they have received funding: JA was member of Advisory boards at Viiv, MSD, Janssen, Abbvie, Gilead and BMS. JR has receiven honoraria for consulting and/or speaking at educational events from Abbvie, Bionor, BMS, Gilead, Janssen, Merck and ViiV. None of the remaining authors have anything to declare.
\end{abstract}

\section{Authors' contributions}

CS analysed the data and drafted the manuscript, JA LP JR critically reviewed the analyses and provided clinical input, JA LP JR AA FB, RZ, GD, CM, JM, SW, $A Z, J C, G C, D R$ reviewed and commented on initial and final drafts of the manuscript, all authors read and approved the final manuscript.

\footnotetext{
Acknowledgements

Analysis and Writing committee: Colette Smit, Joop Arends, Lars Peters, Antonella d'Arminio Monforte, Francois Dabis, Jürgen Kurt Rockstroh, Robert Zangerle, George Daikos, Christina Mussini, Josep Mallolas, Stephane De Wit, Annelies Zinkernagel, Jaime Cosin, Genevieve Chêne and Dorthe Raben on behalf of the Hepatitis C working group of Collaboration of Observational HIV Epidemiological Research in Europe (COHERE) in EuroCoord Steering Committee - Contributing Cohorts: Robert Zangerle (AHIVCOS), Giota Touloumi (AMACS), Josiane Warszawski (ANRS CO1 EPF/ ANRS CO11 OBSERVATOIRE EPF), Laurence Meyer (ANRS CO2 SEROCO), François Dabis (ANRS CO3 AQUITAINE), Murielle Mary Krause (ANRS CO4 FHDH), Jade Ghosn (ANRS CO6 PRIMO), Catherine Leport (ANRS CO8 COPILOTE), Linda Wittkop (ANRS CO13 HEPAVIH), Peter Reiss (ATHENA),
}

Ferdinand Wit (ATHENA), Maria Prins (CASCADE), Heiner Bucher (CASCADE), Diana Gibb (CHIPS), Gerd Fätkenheuer (Cologne-Bonn), Julia Del Amo (CoRIS), Niels Obel (Danish HIV Cohort), Claire Thorne (ECS), Amanda Mocroft (EuroSIDA), Ole Kirk (EuroSIDA), Christoph Stephan (Frankfurt), Santiago Pérez-Hoyos (GEMES-Haemo), Osamah Hamouda (German ClinSurv), Barbara Bartmeyer (German ClinSurv), Nikoloz Chkhartishvili (Georgian National HIV/ AIDS), Antoni Noguera-Julian (CORISPE-cat), Andrea Antinori (ICC), Antonella d'Arminio Monforte (ICONA), Norbert Brockmeyer (KOMPNET), Luis Prieto (Madrid PMTCT Cohort), Pablo Rojo Conejo (CORISPES-Madrid), Antoni Soriano-Arandes (NENEXP), Manuel Battegay (SHCS), Roger Kouyos (SHCS), Cristina Mussini (Modena Cohort), Pat Tookey (NSHPC), Jordi Casabona (PISCIS), Jose Miró (PISCIS), Antonella Castagna (San Raffaele), Deborah Konopnick (St. Pierre Cohort), Tessa Goetghebuer (St Pierre Paediatric Cohort), Anders Sönnerborg (Swedish InfCare), Carlo Torti (The Italian Master Cohort), Caroline Sabin (UK CHIC), Ramon Teira (VACH), Myriam Garrido (VACH). David Haerry (European AIDS Treatment Group)

Executive Committee: Stéphane De Wit (Chair, St. Pierre University Hospital), Jose Miró (PISCIS), Dominique Costagliola (FHDH), Antonella d'ArminioMonforte (ICONA), Antonella Castagna (San Raffaele), Julia del Amo (CoRIS), Amanda Mocroft (EuroSIDA), Dorthe Raben (Head, Copenhagen Regional Coordinating Centre), Geneviève Chêne (Head, Bordeaux Regional Coordinating Centre). Paediatric Cohort Representatives: Ali Judd, Pablo Rojo Conejo.

Regional Coordinating Centres: Bordeaux RCC: Diana Barger, Christine Schwimmer, Monique Termote, Linda Wittkop; Copenhagen RCC: Maria Campbell, Casper M. Frederiksen, Nina Friis-Møller, Dorthe Raben, Rikke Salbøl Brandt.

Project Leads and Statisticians: Juan Berenguer, Julia Bohlius, Vincent Bouteloup, Heiner Bucher, Alessandro Cozzi-Lepri, François Dabis, Antonella d'Arminio Monforte, Mary-Anne Davies, Julia del Amo, Maria Dorrucci, David Dunn, Matthias Egger, Hansjakob Furrer, Marguerite Guiguet, Sophie Grabar, Ali Judd, Ole Kirk, Olivier Lambotte, Valériane Leroy, Sara Lodi, Sophie Matheron, Laurence Meyer, Jose Miró, Amanda Mocroft, Susana Monge, Fumiyo Nakagawa, Roger Paredes, Andrew Phillips, Massimo Puoti, Michael Schomaker, Colette Smit, Jonathan Sterne, Rodolphe Thiebaut, Claire Thorne, Carlo Torti, Marc van der Valk, Linda Wittkop, Natasha Wyss. We thank Catriona Ester from the Stichting HIV monitoring for editing the manuscript.

\section{Funding}

The COHERE study group has received unrestricted funding from: Agence Nationale de Recherches sur le SIDA et les Hépatites Virales (ANRS), France; HIV Monitoring Foundation, The Netherlands; and the Augustinus

Foundation, Denmark. The research leading to these results has received funding from the European Union Seventh Framework Programme (FP7/2007-2013) under EuroCoord grant agreement $n^{\circ} 260694$. A list of the funders of the participating cohorts can be found at www.COHERE.org.

Received: 10 March 2015 Accepted: 19 October 2015

Published online: 04 November 2015

\section{References}

1. Bani-Sadr F, Denoeud L, Morand P, Lunel-Fabiani F, Pol S, Cacoub P, et al. Early virologic failure in HIV-coinfected hepatitis $C$ patients treated with the peginterferon-ribavirin combination: does abacavir play a role? J Acquir Immune Defic Syndr. 2007;45(1):123-5.

2. Mira JA, Lopez-Cortes LF, Barreiro P, Tural C, Torres-Tortosa M, de Los SG I, et al. Efficacy of pegylated interferon plus ribavirin treatment in HIV/hepatitis $C$ virus co-infected patients receiving abacavir plus lamivudine or tenofovir plus either lamivudine or emtricitabine as nucleoside analogue backbone. J Antimicrob Chemother. 2008;62(6):1365-73.

3. Vispo E, Barreiro P, Pineda JA, Mira JA, Maida I, Martin-Carbonero L, et al. Low response to pegylated interferon plus ribavirin in HIVinfected patients with chronic hepatitis $C$ treated with abacavir. Antivir Ther. 2008;13(3):429-37.

4. Glue P. The clinical pharmacology of ribavirin. Semin Liver Dis. 1999:19 Suppl 1:17-24.

5. Pineda JA, Mira JA, Gil IL, Valera-Bestard B, Rivero A, Merino D, et al. Influence of concomitant antiretroviral therapy on the rate of sustained virological response to pegylated interferon plus ribavirin in hepatitis $C$ virus/HIV-coinfected patients. J Antimicrob Chemother. 2007;60(6):1347-54. 
6. Laufer N, Laguno M, Perez I, Cifuentes C, Murillas J, Vidal F, et al. Abacavir does not influence the rate of virological response in HIV-HCV-coinfected patients treated with pegylated interferon and weight-adjusted ribavirin. Antivir Ther. 2008;13(7):953-7.

7. Amorosa VK, Slim J, Mounzer K, Bruno C, Hoffman-Terry M, Dorey-Stein Z, et al. The influence of abacavir and other antiretroviral agents on virological response to HCV therapy among antiretroviral-treated HIV-infected patients. Antivir Ther. 2010;15(1):91-9.

8. Solas C, Pambrun E, Winnock M, Salmon D, Poizot-Martin I, Dominguez S, et al. Ribavirin and abacavir drug interaction in HIV-HCV coinfected patients: fact or fiction? AIDS. 2012;26(17):2193-9.

9. Berenguer J, Von Wichmann MA, Quereda C, Miralles P, Mallolas J, LopezAldeguer J, et al. Effect of accompanying antiretroviral drugs on virological response to pegylated interferon and ribavirin in patients co-infected with HIV and hepatitis C virus. J Antimicrob Chemother. 2011;66(12):2843-9.

10. Wai CT, Greenson JK, Fontana RJ, Kalbfleisch JD, Marrero JA, Conjeevaram $\mathrm{HS}$, et al. A simple noninvasive index can predict both significant fibrosis and cirrhosis in patients with chronic hepatitis C. Hepatology. 2003;38(2):518-26.

11. Hoggard PG, Kewn S, Barry MG, Khoo SH, Back DJ. Effects of drugs on 2',3'dideoxy-2',3'-didehydrothymidine phosphorylation in vitro. Antimicrob Agents Chemother. 1997;41(6):1231-6.

12. Nunez M, Ocampo A, Aguirrebengoa K, Cervantes M, Pascual A, Echeverria $S$, et al. Incidence of anaemia and impact on sustained virological response in HIV/HCV-coinfected patients treated with pegylated interferon plus ribavirin. J Viral Hepat. 2008;15(5):363-9.

13. EACS. EACS Guidelines version7.02, June 2014. In: European AIDS Clinical Society. 2014

14. Sulkowski MS, Wasserman R, Brooks L, Ball L, Gish R. Changes in haemoglobin during interferon alpha-2b plus ribavirin combination therapy for chronic hepatitis C virus infection. J Viral Hepat. 2004;11(3):243-50.

15. Rockstroh JK, Peters L, Grint D, Soriano V, Reiss P, Monforte A, et al. Does hepatitis $C$ viremia or genotype predict the risk of mortality in individuals co-infected with HIV? J Hepatol. 2013;59(2):213-20.

16. Opravil M, Rodriguez-Torres M, Rockstroh J, Snoeck E, Chung RT, Tietz A, et al. The dose-response relationship of peginterferon alfa-2a and ribavirin in the treatment of patients coinfected with HIV-HCV. HIV Clin Trials. 2012;13(1):33-45

17. Sulkowski MS, Shiffman ML, Afdhal NH, Reddy KR, McCone J, Lee WM, et al Hepatitis C virus treatment-related anemia is associated with higher sustained virologic response rate. Gastroenterology. 2010;139(5):1602. -11, 1611.

18. Nunez M, Camino N, Ramos B, Berdun MA, Barreiro P, Losada E, et al. Impact of ribavirin exposure on early virological response to hepatitis $C$ therapy in HIV-infected patients with chronic hepatitis C. Antivir Ther. 2005;10(5):657-62.

19. Soriano V, Puoti M, Sulkowski M, Cargnel A, Benhamou Y, Peters M, et al. Care of patients coinfected with HIV and hepatitis C virus: 2007 updated recommendations from the HCV-HIV International Panel. AIDS. 2007;21(9):1073-89.

20. Carrat F, Bani-Sadr F, Pol S, Rosenthal E, Lunel-Fabiani F, Benzekri A, et al. Pegylated interferon alfa-2b vs standard interferon alfa-2b, plus ribavirin, for chronic hepatitis $\mathrm{C}$ in HIV-infected patients: a randomized controlled trial. JAMA. 2004;292(23):2839-48.

21. Smit C, van den Berg C, Geskus R, Berkhout B, Coutinho R, Prins M. Risk of hepatitis-related mortality increased among hepatitis C virus/HIV-coinfected drug users compared with drug users infected only with hepatitis $C$ virus: a 20-year prospective study. J Acquir Immune Defic Syndr. 2008;47(2):221-5.

22. Graham CS, Baden LR, Yu E, Mrus JM, Carnie J, Heeren T, et al. Influence of human immunodeficiency virus infection on the course of hepatitis $C$ virus infection: a meta-analysis. Clin Infect Dis. 2001;33(4):562-9.

23. Labarga P, Vispo E, Barreiro P, Rodriguez-Novoa S, Pinilla J, Morello J, et al. Rate and predictors of success in the retreatment of chronic hepatitis $C$ virus in HIV/hepatitis C Virus coinfected patients with prior nonresponse or relapse. J Acquir Immune Defic Syndr. 2010;53(3):364-8.

\section{Submit your next manuscript to BioMed Central and take full advantage of:}

- Convenient online submission

- Thorough peer review

- No space constraints or color figure charges

- Immediate publication on acceptance

- Inclusion in PubMed, CAS, Scopus and Google Scholar

- Research which is freely available for redistribution

Submit your manuscript at www.biomedcentral.com/submit 